\title{
Laboratory diagnosis of syphilis: A survey to examine the range of tests used in Canada
}

\author{
Raymond SW Tsang $\mathrm{PhD}^{1}$, Sandra Michelle Radons BSc $\mathrm{Ag}^{1}$, Muhammad Morshed $\mathrm{PhD}^{2,3}$; on behalf of the Syphilis \\ Laboratory Task Group of the Canadian Public Health Laboratory Network
}

\begin{abstract}
RSW Tsang, SM Radons, M Morshed; on behalf of the Syphilis Laboratory Task Group of the Canadian Public Health Laboratory Network. Laboratory diagnosis of syphilis: A survey to examine the range of tests used in Canada. Can J Infect Dis Med Microbiol $2011 ; 22(3): 83-87$.
\end{abstract}

Laboratory diagnosis of syphilis has undergone major changes in the past decade with the introduction of immunoassays and recombinant Treponema pallidum antigens as screening tools for syphilis infection. To address this change in laboratory practice, a national syphilis laboratory working group was established with members from the Public Health Agency of Canada, provincial public health laboratories across the country as well as sexually transmitted infection researchers, clinicians and epidemiologists. This working group aims to examine how the use of newer immunoassays will affect syphilis diagnosis, surveillance and disease management. To provide a baseline for this work, an e-mail survey was conducted in the fall of 2009 to determine current laboratory practices for syphilis diagnosis in Canada. The most commonly used tests were rapid plasma reagin, enzyme immunoassay, $T$ pallidum passive particle agglutination, venereal disease research laboratory, fluorescent treponemal antibody absorption, line immunoassay and polymerase chain reaction with $92 \%, 36 \%, 32 \%, 20 \%, 12 \%$, $12 \%$ and $12 \%$ of the responding laboratories reporting using these tests, respectively. The ultimate goal of this working group will be to update laboratory guidelines for the diagnosis of syphilis, and to identify syphilis surveillance and research priorities in Canada.

\section{Le diagnostic de syphilis en laboratoire : une enquête pour examiner la série de tests utilisés au Canada et ses conséquences}

\begin{abstract}
Le diagnostic de syphilis en laboratoire a subi d'énormes changements depuis dix ans en raison de l'introduction des dosages immunologiques et des antigènes recombinants de Treponema pallidum comme outils de dépistage de l'infection à la syphilis. Afin de se pencher sur ce changement de pratique en laboratoire, un groupe de travail national de laboratoires sur la syphilis a été formé, composé de membres de l'Agence de la santé publique du Canada, de laboratoires provinciaux de santé publique du pays et de chercheurs, de cliniciens et d'épidémiologistes spécialisés en infections transmises sexuellement. Ce groupe de travail vise à examiner en quoi l'utilisation des nouveaux dosages immunologiques influera sur le diagnostic, la surveillance et la prise en charge de la syphilis. Afin de fournir des données de base à cette étude, l'équipe a mené une enquête par courriel à l'automne 2009 afin de déterminer les pratiques de laboratoire utilisées pour diagnostiquer la syphilis au Canada. Les tests les plus utilisés étaient l'anticorps réaginique, l'épreuve immunoenzymatique, l'agglutination passive de particules de $T$ pallidum, le VDRL, le test d'immunofluorescence absorbée, le dosage immunoenzymatique en ligne et la réaction en chaîne de la polymérase, 92 \%, 36 \%, 32 \%, $20 \%$, $12 \%, 12 \%$ et $12 \%$ des laboratoires répondants utilisant ces tests, respectivement. Le groupe de travail s'est donné comme objectif ultime de mettre à jour les lignes directrices pour diagnostiquer la syphilis en laboratoire et de déterminer les priorités de surveillance de la syphilis et de recherche sur cette maladie au Canada.
\end{abstract}

Key Words: Algorithms; Diagnosis; Serology; Syphilis

\begin{tabular}{|c|c|}
\hline $\begin{array}{l}\text { Treponema pallidum is a highly fastidious organism that is difficult to } \\
\text { culture (1). Consequently, the laboratory diagnosis of syphilis has } \\
\text { traditionally been performed either using microscopy (dark field, silver } \\
\text { staining or fluorescent antibody assay) or serology. The rabbit infectivity } \\
\text { assay has long been regarded as a research tool, but is seldom performed } \\
\text { as a diagnostic test in Canada. Dark field microscopy was a popular } \\
\text { choice for the detection of the classical corkscrew motile spirochetes } \\
\text { from chancres. However, the requirement for specific expertise in dark } \\
\text { field microscopy and the need to view the slides within minutes of speci- } \\
\text { men collection means that it is only feasible in clinics specializing in } \\
\text { sexually transmitted infections (STIs). Other microscopic techniques, } \\
\text { namely silver staining or direct fluorescent antibody, although available, } \\
\text { have not been widely adopted by diagnostic laboratories for making a } \\
\text { primary diagnosis. In Canada, serology is the primary laboratory method } \\
\text { for the diagnosis of syphilis. With the greater availability of molecular } \\
\text { technologies in many mid-size clinical laboratories, it is likely that } \\
\text { molecular methods for detection of this organism in chancres and other } \\
\text { sample types will be used more often, although, at present, such assays } \\
\text { are not commercially available. }\end{array}$ & $\begin{array}{l}\text { The serological diagnosis of syphilis has conventionally been div- } \\
\text { ided into nontreponemal test (NTT) and treponemal test (TT) for } \\
\text { measuring syphilis antibodies. Nontreponemal assays, best exemplified } \\
\text { by the rapid plasma reagin (RPR) test and the venereal disease } \\
\text { research laboratory (VDRL) test, detect reagin-based antibodies pro- } \\
\text { duced as a primary response to treponemal infection. Although non- } \\
\text { specific in origin, their presence in high or rising titres is highly } \\
\text { predictive of recent infection. While immediate and effective treat- } \\
\text { ment results in a rapid titre decline, untreated individuals will also } \\
\text { show a less dramatic, but measurable decline in antibody levels, } \\
\text { resulting in a low and sometimes stable titre in the late latent and } \\
\text { tertiary stages of their disease. In contrast, treponemal-specific assays, } \\
\text { such as the microhemagglutination assay for antibodies to T pallidum } \\
\text { and the T pallidum passive particle agglutination (TP-PA) test, detect } \\
T \text { pallidum-specific antibodies, which often persist lifelong despite } \\
\text { effective treatment. Consequently, many diagnostic algorithms use an } \\
\text { NTT to screen for early disease sometimes in combination with a TT } \\
\text { to determine past infection status depending on individual patient } \\
\text { scenarios. }\end{array}$ \\
\hline
\end{tabular}

${ }^{1}$ National Microbiology Laboratory, Public Health Agency of Canada, Winnipeg, Manitoba; ${ }^{2}$ Public Health Microbiology and Reference Laboratory, British Columbia Centre for Disease Control, Provincial Health Services Authority, ${ }^{3}$ Department of Pathology and Laboratory Medicine, University of British Columbia, Vancouver, British Columbia

Correspondence: Dr Raymond SW Tsang, National Microbiology Laboratory, 1015 Arlington Street, Winnipeg, Manitoba R3E 3R2.

Telephone 204-789-6020, fax 204-789-2018, e-mail raymond.tsang@phac-aspc.gc.ca 
TABLE 1

The types and number of laboratories in each province and territory* performing syphilis testing in Canada

\begin{tabular}{|c|c|c|}
\hline Province & Laboratory type & $\mathrm{n}$ \\
\hline \multirow[t]{3}{*}{ British Columbia } & $\mathrm{PHL}$ & 1 \\
\hline & Hospital & - \\
\hline & Private & - \\
\hline \multirow[t]{3}{*}{ Alberta } & $\mathrm{PHL}$ & 1 \\
\hline & Hospital/regional & 1 \\
\hline & Private & 1 \\
\hline \multirow[t]{3}{*}{ Saskatchewan } & $\mathrm{PHL}$ & 1 \\
\hline & Hospital & - \\
\hline & Private & - \\
\hline \multirow[t]{3}{*}{ Manitoba } & $\mathrm{PHL}$ & 1 \\
\hline & Hospital & - \\
\hline & Private & - \\
\hline \multirow[t]{3}{*}{ Ontario } & $\mathrm{PHL}$ & 1 \\
\hline & Hospital & - \\
\hline & Private & - \\
\hline \multirow[t]{3}{*}{ Quebec } & $\mathrm{PHL}$ & 1 \\
\hline & Hospital & $>80$ \\
\hline & Private & 4 \\
\hline Newfoundland and & $\mathrm{PHL}$ & 1 \\
\hline \multirow[t]{2}{*}{ Labrador } & Hospital & 1 \\
\hline & Private & - \\
\hline \multirow[t]{3}{*}{ Prince Edward Island } & $\mathrm{PHL}$ & - \\
\hline & Hospital & 1 \\
\hline & Private & - \\
\hline \multirow[t]{3}{*}{ New Brunswick } & $\mathrm{PHL}$ & - \\
\hline & Hospital & 5 \\
\hline & Private & - \\
\hline \multirow[t]{3}{*}{ Nova Scotia } & $\mathrm{PHL}$ & - \\
\hline & Hospital & 10 \\
\hline & Private & - \\
\hline
\end{tabular}

${ }^{*}$ The General Hospital in Nunavut performed screening using the rapid plasma reagin test; positive samples were forwarded to the Alberta Provincial Public Health Laboratory for confirmation, while in Northwest Territories and Yukon, syphilis testing was provided by a private laboratory in Alberta and the British Columbia Centre for Disease Control, respectively. PHL Public Health Laboratory

Before recombinant DNA technology became a tool for antigen or antibody reagent production, treponemal serological tests used either crude extracts from the $T$ pallidum microorganism ( $T$ pallidum hemagglutination or TP-PA tests) or the whole bacteria (fluorescent treponemal antibody absorption test). Recently, antigens of interest have been cloned from $T$ pallidum and expressed as soluble recombinant proteins for use in modern immunoassays, such as enzyme immunoassay (EIA), an approach that has been widely adapted for bacterial and viral serological diagnostic assays. A significant advantage of these treponemalspecific EIAs on automated platforms is the ability to screen a large number of samples for syphilis, either as part of a panel of other tests or specifically for this organism. An additional advantage is the ability to objectively interpret the results, which are expressed as a value or quotient, thus reducing the need for specialized skills in reading flocculation or hemagglutination-based tests. However, these assays are still in their infancy, and their sensitivity and specificity in detecting various stages of syphilis are still not well characterized in large-scale studies. Consequently, there is still a significant requirement to understand the clinical role and interpretation of these assays, and to compare these results with those obtained through established syphilis serological methods.

Since 1982, the WHO has recommended screening for syphilis using both an NTT and a TT (2). Until recently, the diagnostic algorithm most widely used in Canada has been screening with an NTT and confirmation with a TT. With the introduction of newer diagnostic tests, however, this conventional two-step approach has been challenged. Based on discussions with interested parties, a working group within the Canadian Public Health Laboratory Network has been established to examine the issues of laboratory diagnosis of syphilis in light of the changing practices in the clinical laboratory. The present report describes the findings of a survey of tests currently used in various laboratories across Canada for the diagnosis of syphilis.

\section{METHODS}

Provincial public health laboratory directors or their delegates representing each of the 10 provinces in Canada (British Columbia, Alberta, Saskatchewan, Manitoba, Ontario, Quebec, New Brunswick, Nova Scotia, Prince Edward Island, and Newfoundland and Labrador) were requested to supply the Canadian Public Health Laboratory Network with a contact list of all laboratories within their province that performed syphilis testing. All laboratories conducting syphilis testing, including provincial public health laboratories, hospital and private laboratories, were contacted and supplied with a survey to complete. Participants were requested to identify the type of serological tests used in their laboratories and their use (either as a screening or a confirmatory test), the approximate volume of specimens handled in one year (from January 1 to December 31, 2008), the use of polymerase chain reaction (PCR) and 'point of care' testing for syphilis, and the type of laboratory (reference or not). Twenty-nine laboratories - including the Laboratoire de santé publique du Québec (LSPQ), but not other types of laboratories in Quebec (see below) - that were identified as users of diagnostic syphilis testing were provided with the questionnaire electronically and were given three weeks to respond by either mail, fax or e-mail.

Because a similar survey of approximately 90 laboratories within Quebec was recently performed by the Institut national de santé publique du Québec to examine the laboratory practices for syphilis testing (3), the LSPQ summarized the findings from their survey into a single response.

The types and number of laboratories from each province that participated in the present survey are listed in Table 1.

\section{RESULTS}

\section{Laboratories that provide syphilis testing in Canada}

Twenty-five of 29 laboratories (including the LSPQ, which summarized responses from all relevant laboratories in Quebec) responded to the survey, corresponding to a response rate of $86 \%$. The composition of the 25 responding laboratories included provincial public health laboratories in each of the provinces mentioned above plus 15 regional/ hospital/or private laboratories in New Brunswick, Nova Scotia, Newfoundland and Labrador, Prince Edward Island and Alberta (Table 1). Diagnostic testing in the territories varied: the General Hospital in Nunavut performed screening using the RPR test and the positive samples were forwarded to the Alberta Provincial Public Health Laboratory for confirmation, while in the Northwest Territories and Yukon, syphilis testing was conducted by a private laboratory in Alberta and confirmed at the Alberta Provincial Public Health Laboratory and the British Columbia Centre for Disease Control (BCCDC), respectively.

In some provinces, syphilis serology testing was centralized at the provincial public health laboratory; while in other provinces (eg, Quebec), there were more than 80 laboratories providing the initial screening test. In 2008, the approximate number of specimens processed per year in individual laboratories ranged from 450 to 500,000 specimens. Four provincial public health laboratories processed more than 100,000 specimens in 2008 (BCCDC's Public Health Microbiology \& Reference Laboratory: 154,000; Alberta Provincial Public Health Laboratory: 118,000; LSPQ: 188,000 and Ontario's Public Health Agency Laboratory: 500,000). The mean and median number of specimens processed by all laboratories in 2008 were 46,614 and 3341, respectively. 


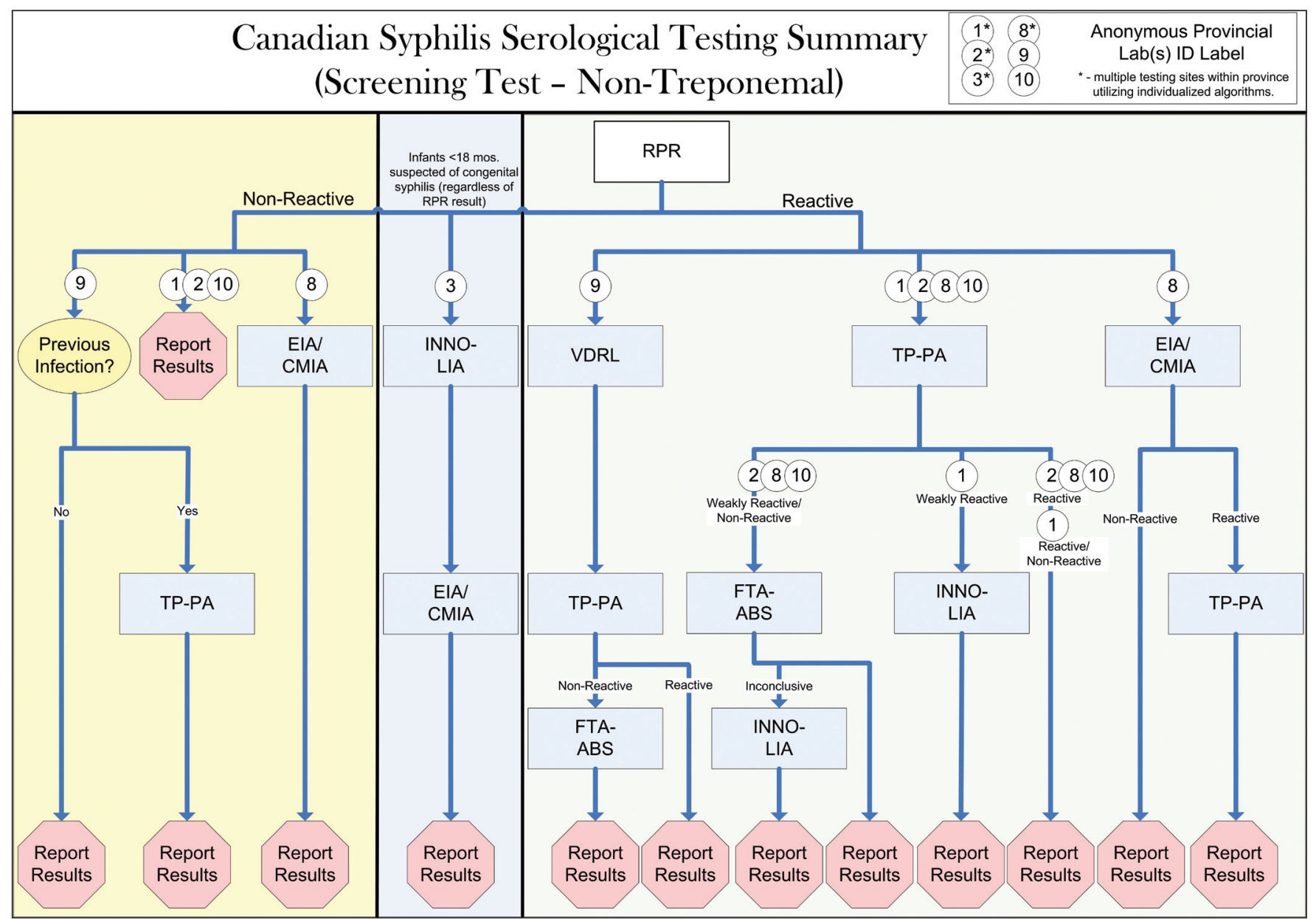

Figure 1) Summary of algorithms used in some Canadian laboratories for the diagnosis of syphilis: Screening with nontreponemal tests. INNO-LIA (Innogenetics NV, Belgium). CMIA Chemiluminescent microplate immunoassay; EIA Enzyme immunoassay; FTA-ABS Fluorescent treponemal antibody absorption; ID Identification; Lab Laboratory; mos Months; RPR Rapid plasma reagin; TP-PA Treponema pallidum passive particle agglutination; VDRL Venereal disease research laboratory

\section{Laboratory testing for syphilis}

Of the 25 responding laboratories, 23 (92\%) performed the traditional nontreponemal screening RPR test. Only two laboratories did not perform this test; they used EIA or chemiluminescent microplate immunoassay (CMIA) for syphilis serology. The sources of the RPR antigen or test kit used by six of the responding laboratories included the Pulse RPR kit (Pulse Scientific Inc, Canada), the Macro-Vue RPR kit (Becton Dickinson, Canada), the Wampole Impact RPR kit (Inverness Medical Professional Diagnostics, USA) and the Syphilis Randox RPR test (Randox Laboratories Canada Ltd). Seventeen of the 23 laboratories that used the RPR test did not provide additional details regarding the antigens or test kits used.

Only seven laboratories in the provinces of Prince Edward Island, Nova Scotia, Quebec, Ontario, Manitoba, Alberta and British Columbia were using the nontreponemal VDRL test; and five laboratories indicated that this test was solely used for testing of cerebral spinal fluid.

Of the conventional TTs, eight laboratories in the provinces of Prince Edward Island, Nova Scotia, Newfoundland and Labrador, Quebec, Ontario, Manitoba, Saskatchewan and British Columbia were using the TP-PA as their standard test, while only four laboratories (the provincial public health laboratories in British Columbia, Alberta, Manitoba and Ontario) were using the fluorescent treponemal antibody absorption test as their secondary test to resolve any indeterminate findings. Three provincial public health laboratories in British Columbia, Alberta and Quebec were also using the line immunoassay for the detection of treponemal-specific antibodies; these tests were mainly used for confirmation or to resolve difficult clinical cases.

Nine laboratories in the provinces of Alberta, Saskatchewan, Ontario, Quebec, Nova Scotia, New Brunswick and Prince Edward Island were using immunoassays (either EIA or CMIA) for syphilis serology testing. Of the nine laboratories that reported using immunoassays, three were using the Abbott Architect system (Abbott Laboratories, USA), and the rest of the laboratories reported using tests that included the Captia Syphilis IgG (Bio-Rad Laboratories Ltd, Canada), Enzygnost Syphilis (Siemens Canada Ltd), TrepSure and Trep-Check (Phoenix Bio-Tech Corp, Canada) and Radim syphilis screening (Radim SpA, Italy). Three laboratories did not specify the type of immunoassays that they were using.

Three laboratories in the provinces of British Columbia, Alberta and Quebec indicated that other tests were also used and they included one or both of the following: dark field microscopy and direct immunofluorescent antibody testing. Dark field microscopy was mostly performed in primary laboratories associated with hospitals or STI clinics.

Two laboratories - BCCDC's Public Health Microbiology \& Reference Laboratory and the Alberta Provincial Public Health Laboratory - provided PCR testing for detection of syphilis in clinical specimens.

The different algorithms used in Canada for the serological diagnosis of syphilis are depicted in Figures 1 and 2. The two general approaches can be summarized as either screening using the conventional RPR tests and confirmation by TTs (TP-PA, EIA, CMIA, etc) 


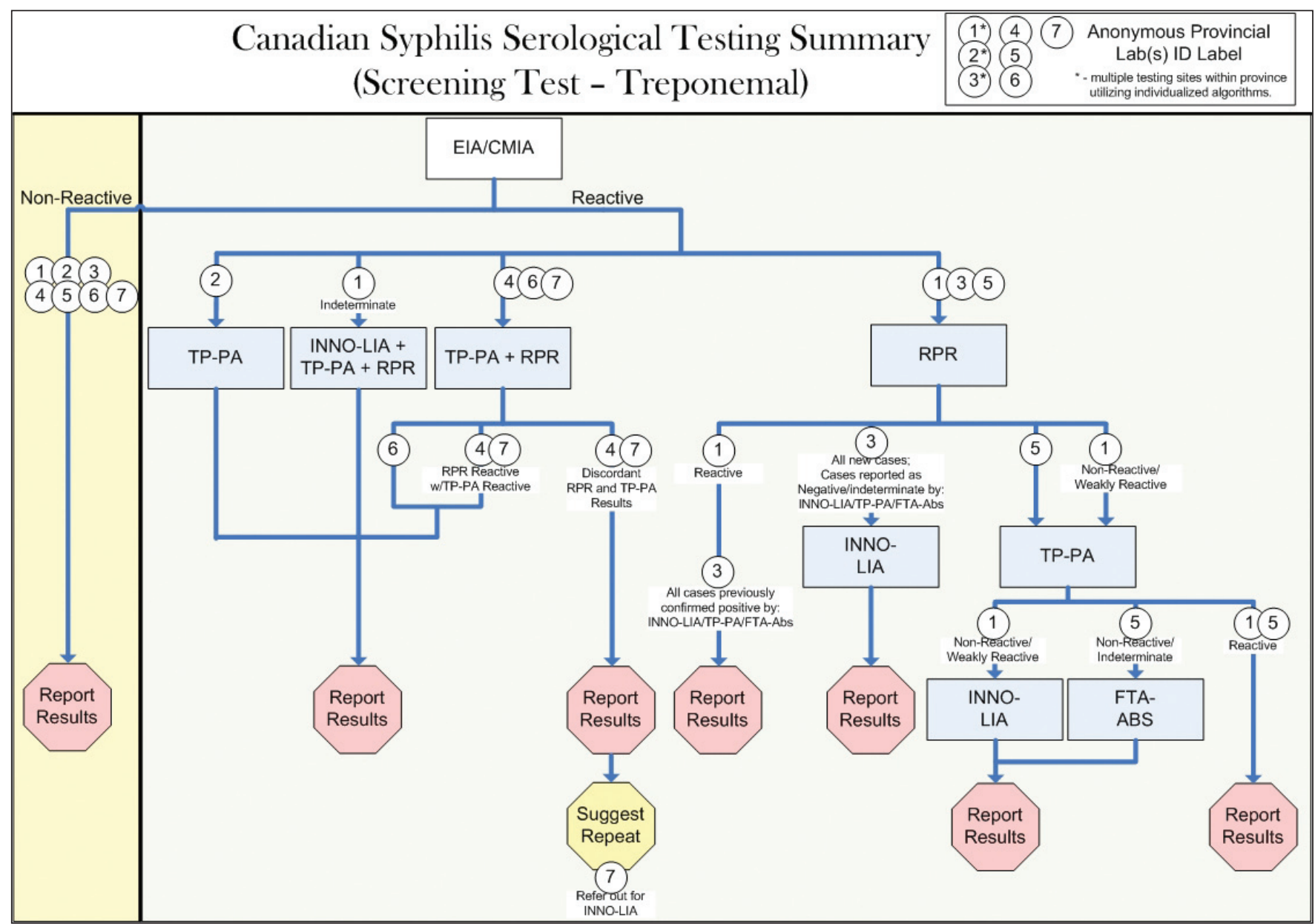

Figure 2) Summary of algorithms used in some Canadian laboratories for the diagnosis of syphilis: Screening with treponemal immunoassays. INNO-LIA (Innogenetics NV, Belgium). CMIA Chemiluminescent microplate immunoassay; EIA Enzyme immunoassay; FTA-ABS Fluorescent treponemal antibody absorption; ID Identification; Lab Laboratory; RPR Rapid plasma reagin; TP-PA Treponema pallidum passive particle agglutination; w/ With

or screening using TTs and confirmation of infection status using the RPR test.

\section{DISCUSSION}

Of the 25 laboratories that participated in the survey, the most commonly used laboratory test for syphilis diagnosis was RPR (92\% of the laboratories), followed by newer immunoassays such as EIA or CMIA (36\%), TP-PA (32\%), VDRL (20\%), and line immunoassay or PCR ( $12 \%$ for each method). The laboratory practice for syphilis diagnosis in Canada is different from that in England and Wales (United Kingdom). A recent survey (4) found that $94 \%$ of the laboratories in England and Wales were using EIA, followed by RPR/VDRL (41\%), TP-PA or T pallidum hemagglutination (34\%), and treponemal EIA that specifically detected immunoglobulin M antibodies (10\%) (4).

The high volume of specimens processed in some of the laboratories, the variability in the methods and test kits used plus a low prevalence of the disease in parts of Canada makes the laboratory investigation of syphilis infection challenging. One important component in the laboratories performing syphilis testing is participation in a proficiency program to ensure that both the laboratory method and the reagents used are controlled and monitored for quality on a regular basis. The National Microbiology Laboratory (Winnipeg, Manitoba) hosts a proficiency program on syphilis serology, and it distributes five qualitycontrol samples twice a year to 30 laboratories in Canada. Some laboratories also participate in other proficiency programs such as the College of American Pathologists proficiency program. Participation in proficiency testing becomes even more important as new methods are increasingly introduced into the diagnostic laboratories. In the past two decades, diagnostic laboratories have witnessed the introduction of EIAs or CMIAs for syphilis serology, which have challenged the conventional view of screening with an NTT followed by confirmation with a TT.

The use of automated immunoassays is becoming increasingly common among laboratories that provide syphilis serological testing. Of the 25 Canadian laboratories that participated in a survey in 2009, nine were using some form of EIA or CMIA. Because these newer immunoassays are more sensitive (able to capture previously treated, untreated and new infections) than the traditional serological tests $(5,6)$, they may be more suitable than the conventional NTTs (only able to capture untreated or new infections) to screen for syphilis infection. The introduction of EIA or CMIA for syphilis screening in some laboratories is probably related to the higher sensitivity of these assays, the increased volume of testing recently experienced in some provinces as a result of a resurgence in syphilis infections, and the ability of these newer methods to be automated; therefore, these assays have advantages over the conventional laborious manual methods. However, a single positive EIA or CMIA result only implies the presence of antibodies to $T$ pallidum; some form of confirmatory testing is required. Moreover, the possibility of a false-positive EIA or CMIA result has not been adequately addressed. In addition, an NTT, such as the RPR titre, is still required to help with staging the infection, determining response to treatment and assessing for reinfection.

A brief review of the diagnostic algorithms used in Canada for syphilis serology revealed considerable complexity and variability among laboratories. Even with the traditional approach of screening with an NTT followed by confirmation with a TT (Figure 1), interpreting the 
multitude of serological tests to diagnose syphilis can be a challenging task. The incorporation of treponemal EIA for syphilis screening - evident in both the surveys performed in the United Kingdom (4) and in our study - adds another level of complexity. The experience of one Canadian city that adopted treponemal EIA for screening has highlighted some potential effects of this changeover in the methodology of syphilis epidemiology in the community (7). To address these issues and the change in the practice of the diagnostic laboratory, the Public Health Agency of Canada is consulting with provinces and territories to re-examine and possibly revise the conventional diagnostic algorithms for syphilis serology in Canada. A working group has been formed within the Canadian Public Health Laboratory Network's Laboratory Standards Issue Group to determine the issues related to laboratory diagnosis of syphilis, and to develop guidelines that may help to standardize algorithm testing and interpretation of the many laboratory tests used in its diagnosis. This working group is comprised of representatives from federal and provincial public health laboratories as well as STI clinicians, researchers and epidemiologists. The scope of work by this group includes the following:

- Reviewing the current literature on laboratory diagnosis of syphilis;

- Identifying gaps for further research in the area of laboratory screening and confirmation of syphilis; and

- Updating guidelines for the laboratory diagnosis of syphilis.

\section{SUMMARY}

We have provided a snapshot of the types of laboratory tests being performed for syphilis diagnosis by different clinical laboratories across Canada. The use of EIA or CMIA has created the need to examine diagnostic algorithms for the laboratory diagnosis of syphilis and the impact of the application of these newer assays on the surveillance case definition of syphilis - a nationally notifiable infection. A federal-provincial laboratory working group has been established to review current laboratory methods in Canada and to examine how the newer immunoassays for syphilis may affect diagnosis, surveillance and disease management.

ACKNOWLEDGEMENTS: The authors thank the participating laboratories for providing information through the survey.
Members of the Syphilis Laboratory Task Group (in alphabetical order): Vanessa Allen MD FRCPC, Ontario Agency for Health Protection and Promotion; Lei Ang MBChB FRCPath, Queen Elizabeth Hospital, Prince Edward Island; Ron Ballard PhD, Centers for Disease Control and Prevention, USA; Max Chernesky PhD, McMaster University, Ontario; Magdy Dawood PhD, Cadham Provincial Public Health Laboratory, Manitoba; Kevin Fonseca PhD, Alberta Health Services; Richard Garceau MD CSPQ FRCPC, Hopital Dr George L Dumont, New Brunswick; Gayatri Jayaraman MPH PhD, Centre for Communicable Diseases and Infection Control, Public Health Agency of Canada; Bonita E Lee MD FRCPC MSc, University of Alberta; Paul Levett PhD (D)ABMM FCCM FAAM, Saskatchewan Disease Control Laboratory; Muhammad Morshed PhD, British Columbia Centre for Disease Control; Bouchra Serhir PhD, Institut national de santé publique du Québec; Ameeta Singh BMBS MSc, University of Alberta; Raymond Tsang PhD, National Microbiology Laboratory, Public Health Agency of Canada; Tom Wong MD, Centre for Communicable Diseases and Infection Control, Public Health Agency of Canada.

\section{REFERENCES}

1. Fieldsteel, AH, Cox, DL, Moeckli, RA. Cultivation of virulent Treponema pallidum in tissue culture. Infect Immun 1981;32:908-15.

2. Report of a WHO Scientific Group. Treponemal infections. $<$ http://whqlibdoc.who.int/trs/WHO_TRS_674.pdf > (Accessed on June 20, 2011).

3. Fortin C, Serhir B, Fleury E. Rapport du sous-comité Épreuves de détection de la syphilis. Institut national de santé publique du Québec, 2010. <www.inspq.qc.ca/publications/notice.asp?E $=$ p\& NumPublication=1031> (Accessed on June 20, 2011).

4. Amin AK, Manuel RJ, Ison CA, et al. Audit of laboratory diagnostic methods for syphilis in England and Wales. Sex Transm Infect 2009;85:88-91

5. Young H, Moyes A, Seager L, McMillan A. Novel recombinant antigen enzyme immunoassay for serological diagnosis of syphilis. J Clin Microbiol 1998;36:913-7.

6. Marangoni A, Moroni A, Accardo S, Cevenini R. Laboratory diagnosis of syphilis with automated immunoassays. J Clin Lab Analysis 2009;23:1-6.

7. Mishra S, Boily M-C, Ng V, et al. The laboratory impact of changing syphilis screening from the rapid plasma reagin to a treponemal enzyme immunoassay: A case-study from the Greater Toronto Area. Sex Transm Dis 2011;38:190-6. 


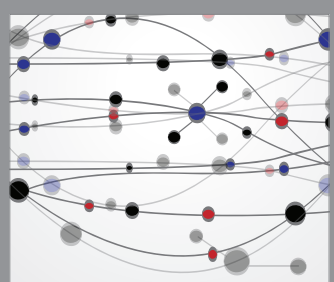

The Scientific World Journal
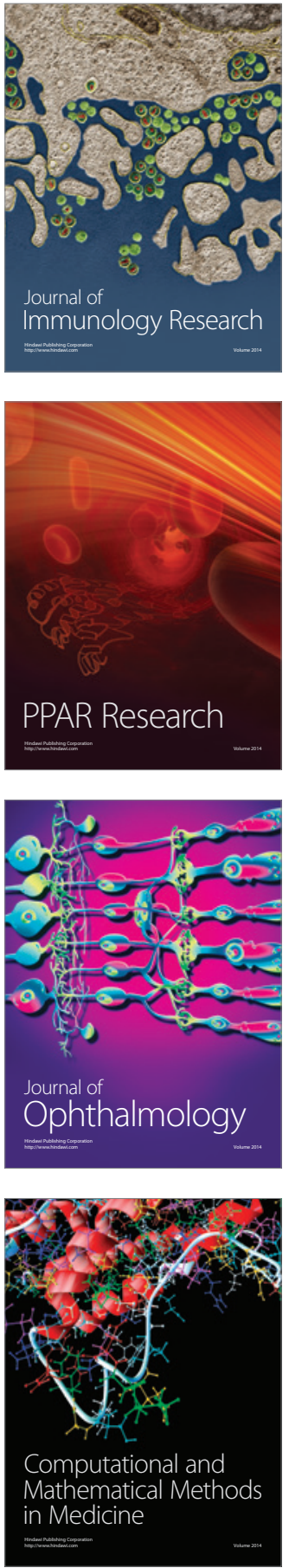

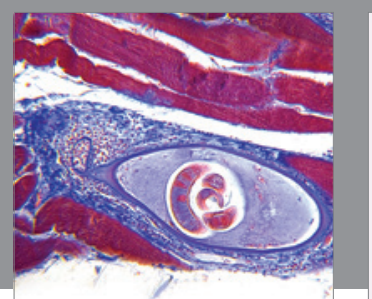

Gastroenterology Research and Practice

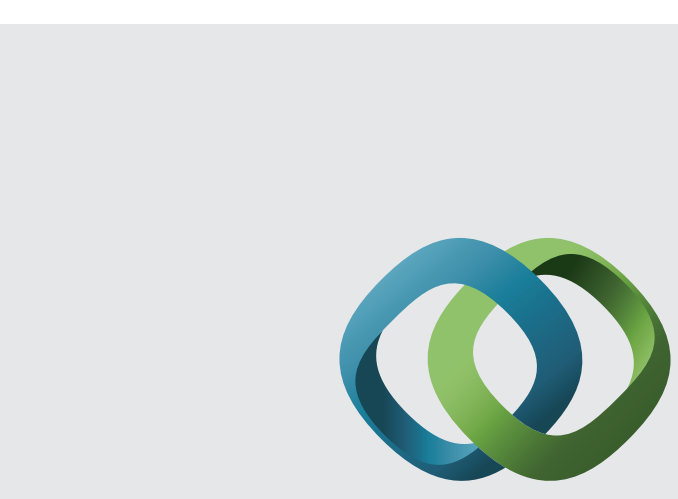

\section{Hindawi}

Submit your manuscripts at

http://www.hindawi.com
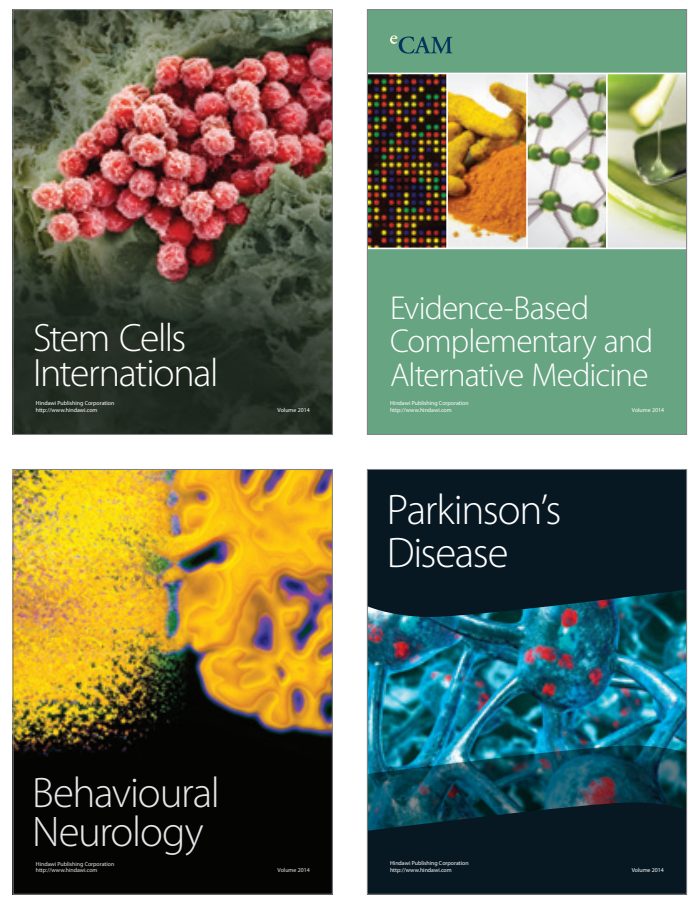
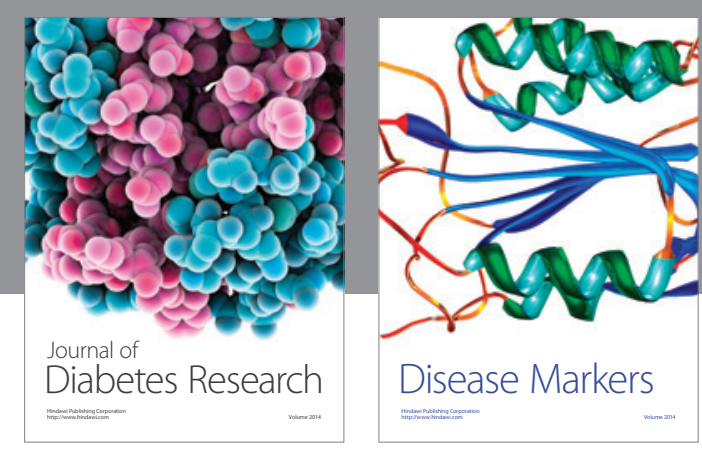

Disease Markers
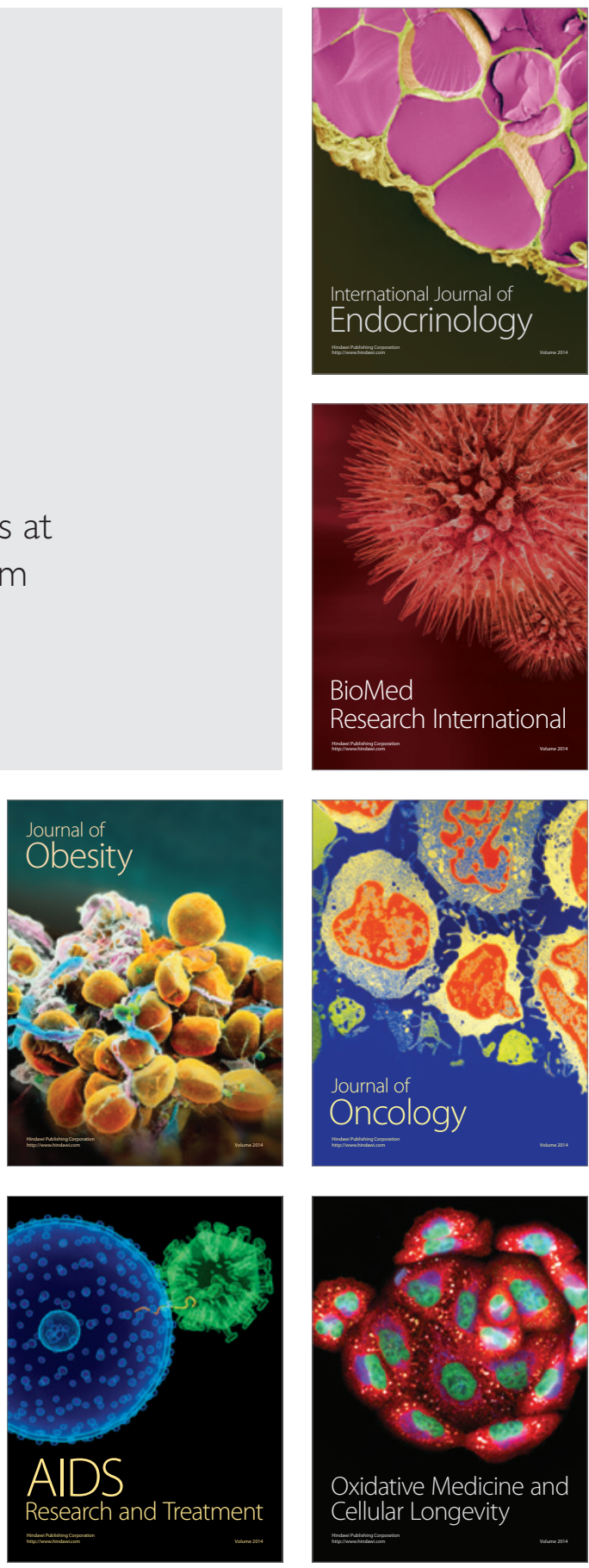